\title{
EFFECT OF PART-TIME PATCHING THERAPY ON VISUAL OUTCOME IN PATIENTS WITH ANISOMETROPIC AMBLYOPIA VISITING AFIO RAWALPINDI
}

\author{
Ammarah Ashraf, Hannan Masud, Shafaq Rabbani, Palwasha Noor \\ Armed Forces Institute of Ophthalmology/National University of Medical Sciences (NUMS) Rawalpindi Pakistan
}

\begin{abstract}
Objective: To determine the effect of amblyopia patching therapy on visual outcome in young and adults at $6^{\text {th }}$ and $12^{\text {th }}$ week. Study Design: Quasi-experimental study.

Place and Duration of Study: Armed Forces Institute of Ophthalmology Rawalpindi, Pakistan, from Sep 2018 to Jan 2020.

Methodology: Out of 110, follow up was successfully completed by 91 eyes. Subjects were divided into young and adult based on age. Age ranging from 5-12 years included in the young group and adult group included those ranging from 13-20 years. Anisometropic amblyopia was considered. Amblyopia due to any other disease were excluded. Subjects were advised patching therapy daily for 4 hours in the affected eye. Follow up was 3 weekly for 12 weeks and the effect of patching therapy was assessed by visual improvement. Statistical analysis was done with SPSS version 21.

Result: Out of 91 eyes with amblyopia, 51 (56.6\%) were included in the young group while 40 (43.4\%) were included in the adult group. In the young group, visual improvement was seen in 40 (78.4\%) while in the adult group 24 (60\%) showed improvement in vision. Mean visual improvement in young was $1.66 \pm 1.099$ while $1.03 \pm 0.944$ in the adult group. Maximum visual improvement in both groups was seen till the $6^{\text {th }}$ week of patching.

Conclusion: Patching therapy is effective even at later ages too. However, continuing patching for more than 6 weeks doesn't show much improvement in vision.
\end{abstract}

Keywords: Amblyopia, Patching therapy, Visual improvement.

How to Cite This Article: Ashraf A, Masud H, Rabbani S, Noor P. Effect of Part-Time Patching Therapy on Visual Outcome in Patients with Anisometropic Amblyopia Visiting AFIO Rawalpindi. Pak Armed Forces Med J 2021; 71(5): 1774-1777. doi: https://doi.org/10.51253/pafmj.v71i5.5525

This is an Open Access article distributed under the terms of the Creative Commons Attribution License (https://creativecommons.org/licenses/by-nc/4.0/), which permits unrestricted use, distribution, and reproduction in any medium provided the original work is properly cited.

\section{INTRODUCTION}

Amblyopia is a condition in which there is the deterioration of vision in one or both eyes in the absence of structural ocular pathology and is considered to be due to inefficient neuronal connection between the eye and cortical pathway ${ }^{1}$. Amblyopia occurs in childhood during the critical period of visual development. Due to the increase in the incidence of refractive errors, amblyopia is becoming very common in children. Prevalence worldwide is ranging between $0.2-6.2 \%{ }^{2}$. Another study, the Avon Longitudinal Study of Parents and Children (ALSPAC) study conducted in the United Kingdom found that one in every 30 children of 7 years of age had amblyopia ${ }^{3}$. The prevalence of amblyopia in Pakistan ranges between 3-6.7\% ${ }^{4-5}$.

Amblyopia is mainly of three types depending upon the underlying cause; strabismic amblyopia, deprivation amblyopia and anisometropic amblyopia. Amblyopia due to misalignment of eyes is labelled as strabismic amblyopia ${ }^{6}$. Deprivation amblyopia is because of insufficient visual stimulus ${ }^{7}$. Anisometropic

Correspondence: Dr Ammara Ashraf, Department of Ophthalmology, Armed Forces Institute of Ophthalmology, Rawalpindi Pakistan Received: 26 Oct 2020; revision received: 25 Nov 2020; accepted: 27 Nov 2020 amblyopia is caused by unequal refractive errors between two eyes ${ }^{8}$. Different treatment strategies opted with time for the treatment of amblyopia but penalisation with patching remained the mainstay. Patching is done to make weaken eye stronger by inhibiting visual stimulus from the stronger eye. Previously, it was believed that only children $<8$ years of age respond to patching therapy but recent studies showed that due to neural plasticity, amblyopia in older patients could also be minimized ${ }^{9}$.

It is presumed that commencing treatment at an early age is more effective than in older. This study will help us in knowing how much patching therapy is effective in the reversal of amblyopia in young and adults. In addition, after how many weeks maximum effect of patching therapy is achieved.

\section{METHODOLOGY}

After taking approval from institutional ethics committee, this quasi experimental study was carried out at Armed Forces Institute of Ophthalmology Rawalpindi, Pakistan from September 2018 to January 2020. After informing all the subjects about the study, a written informed consent was taken from all subjects before becoming a part of study. With the help of 
WHO sample size calculator, sample size was calculated taking confidence interval $95 \%$. It came out to be 74 eyes. We recruited 135 eyes of 135 subjects but only 110 patients gave consent so 110 eyes of 110 patients were registered. Ninety one subjects out of 110 showed up on every follow up visit and completed the treatment regimen under supervision. Using non-probability purposive sampling technique, subjects were categorized into young group and adult group.

Inclusion Criteria: Both genders of age ranging from 5-12 years were considered in young group while those ranging from 13-20 years were included in adult group. Only those patients with anisometropic amblyopia (defined as $>0.2 \log$ Mar visual acuity difference between the 2 eyes on one individual) in only one eye were included in the study.

Exclusion Criteria: Amblyopia due to any other ocular or systemic disease was excluded from the study.

Young group included 51 eyes while 40 eyes were included in the dult group. All the subjects in both groups underwent thorough ocular examination. Along with demographic details, Uncorrected, best corrected and pinhole vision was checked. Cycloplegic refraction was assessed with Auto Ref-keratometer (RK-F1, Canon) after instillation of last drop of $1 \%$ cyclopentolate eye drop. Cycloplegia was considered upon dilation of $\geq 6 \mathrm{~mm}$. Extraocular movement was evaluated along with cover test and prism cover-uncover test for both far and near. Anterior and posterior segment was examine with slit lamp.

Refractive error of all subjects was corrected and then penalisation with patching was advised in amblyopic eye. Method of patching was explained to all subjects and their parents. All subjects were advised to wear a patch of size that was completely covering the eye. Parents were advised to do daily 4 hourlypatching of stronger eye during waking hours with glasses on and children were encouraged to play video games, watch cartoons and other visual-attention activities during patching therapy. To make compliance better, parents were asked to supervise their children during therapy and counselled about the mild agitated behaviour of children because of patching the eye with good vision. In addition to look after children during patching hours to avoid accidents. All subjects were reviewed after every 3 weeks, uncorrected and best corrected vision, cycloplegic refraction and prism cover-uncover test was done on every visit. However, results include comparison of visual improvement in young and adult group after 6 weeks and 12 weeks of patching.

Statistical analysis was done using SPSS-21. The term used to describe the data was percentage and mean $\pm S D$. Corrected visual acuities were converted to $\log$ MAR for statistical analysis. The continuous variables such aslog MAR of uncorrected and corrected visual acuities and the induced change in corrected visual acuity was assessed statistically with independent sample t-test ( $p<0.05$ significance level).

\section{RESULTS}

A total of 110 eyes of 110 subjects were recruited in this study. Only 91 subjects completed the treatment regimen. Out of 91 participants with amblyopic conditions, $40(43.4 \%)$ were adults and 51 (56.6\%) were young.

Statistical test of independent samples t-test was applied to generate a comparison between best-corrected visual acuity after 6 and 12 weeks of patching treatment among young and adult patients' eyes. Out of 40 adult eyes, vision improved among $24(60 \%)$ and did not improve in $16(40 \%)$ after 6 weeks of patching treatment as shown in Figure-1.

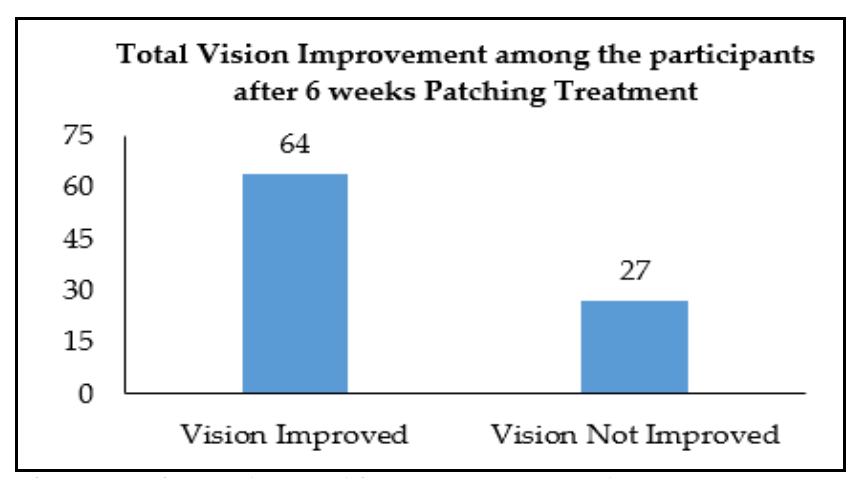

Figure-1: Six weeks patching treatment results.

Whereas, among 51 young patients, 40 (78.4\%) had vision improved and 11 (21.6\%) had no improvement.

Both groups showed improvement in vision with 6 weeks of patching therapy and there was no significant difference established in the improvement of vision between young and adult groups with $p$-value $=$ 0.256 at $95 \%$ CI (-0.054-0.201) with an effect size of 0.01 . This is shown in Table-I.

After another 6 weeks of patching therapy, no further improvement in vision was seen in both the young and adult group. Independent samples t-test showed no significant difference between young and adult patients amblyopic eyes after twelve weeks of 
patching treatment with $p$-value $=0.268,95 \%$ CI $(-0.549$ to 0.195$)$ with an effect size of 0.01 (Table-II).

Table-I: Results of Initial Six weeks patching treatment in amblyopic eye.

\begin{tabular}{l|c|c|c}
\hline $\begin{array}{l}\text { Age } \\
\text { Groups }\end{array}$ & $\begin{array}{c}\text { Vision } \\
\text { Improved (\%) }\end{array}$ & $\begin{array}{c}\text { No Improvement } \\
(\mathbf{\%})\end{array}$ & $\begin{array}{c}\boldsymbol{p} \text { - } \\
\text { value }\end{array}$ \\
\hline Adults & $24(60 \%)$ & $16(40 \%)$ & 0.256 \\
\hline Young & $40(78.4 \%)$ & $11(21.6 \%)$ & $(0.05)$ \\
\hline
\end{tabular}

Table-II: Results of further 6 weeks patching treatment in amblyopic eye seen at the end of 12 weeks.

\begin{tabular}{l|c|c|c}
\cline { 1 - 2 } $\begin{array}{l}\text { Age } \\
\text { Groups }\end{array}$ & $\begin{array}{c}\text { Vision } \\
\text { Improved (\%) }\end{array}$ & $\begin{array}{c}\text { No Improvement } \\
(\%)\end{array}$ & $\begin{array}{c}p- \\
\text { value }\end{array}$ \\
\hline Adults & $24(60 \%)$ & $16(40 \%)$ & 0.268 \\
\cline { 1 - 3 } Young & $40(78.4 \%)$ & $11(21.6 \%)$ & $(0.05)$ \\
\hline
\end{tabular}

A graphical representation showed vision improvement in $40(78.4 \%)$ out of 50 young patients and 24 $(60 \%)$ out of 40 adult patients after twelve weeks of patching treatment. This is shown in Figure-2.

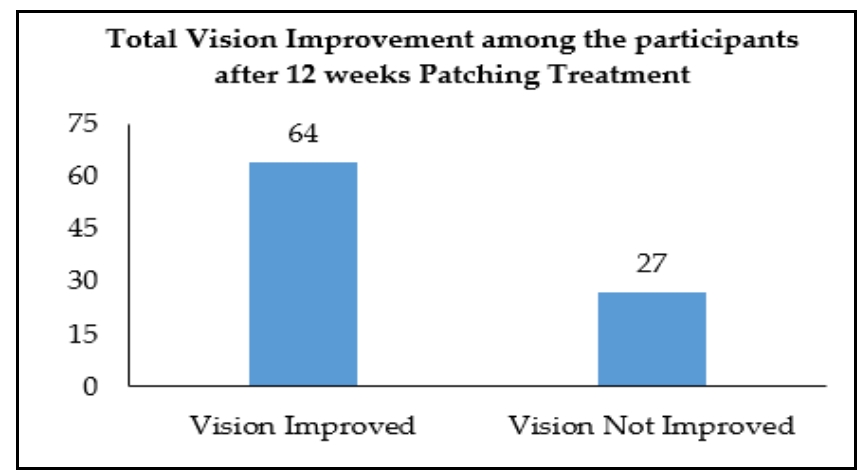

Figure-2: Twelve weeks patching treatment results.

The mean value of visual improvement was taken keeping the minimum improvement as no improvement and maximum improvement was of 3 lines of Snellen chart after 12 weeks of patching.

In the adult group, mean $\pm S D$ was taken of the visual improvement after 12 weeks of patching therapy. In the adult group, it came out to be $1.03 \pm 0.944$ while in the young group the Mean \pm SD was $1.66 \pm$ 1.099 as shown in Table-III.

Table-III: Mean of visual improvement in adult and young group after 12 weeks of patching.

\begin{tabular}{l|c|c|c}
\hline $\begin{array}{l}\text { Age } \\
\text { Groups }\end{array}$ & $\begin{array}{c}\text { Number of } \\
\text { Subjects }\end{array}$ & $\begin{array}{c}\text { Mean Visual } \\
\text { Improvement }\end{array}$ & SD \\
\hline Adult & 24 & 1.03 & 0.944 \\
\hline Young & 40 & 1.66 & 1.099 \\
\hline
\end{tabular}

The descriptive statistics and graphical representation of this study showed that both the young and adult group showed clinically significant improvement with patching therapy in the initial 6 weeks of treatment. However, upon continuing patching therapy for another 6 weeks no significant improvement in bestcorrected visual acuity was seen in both groups. In addition, the mean values show that the visual improvement in both groups is significant and comparable.

\section{DISCUSSION}

The concept of penalization with patching therapy has been used as a treatment of amblyopia for the past 250 years ${ }^{10}$. Before commencing patching therapy, it is very important to correct any refractive error because correction of refractive error makes your patching therapy more efficient and effective ${ }^{11}$. For many years, it was believed that treatment of amblyopia is only effective if started before the age of 7 years ${ }^{12}$. This was so because it was believed if visual development during the critical period was interrupted, there will be an inefficient cortical visual pathway and hence severe visual impairment. However, recent studies showed that the cortical plasticity does not diminish at the age of 7 years; instead, it is present, though decreased, till the age of 50 years $^{13}$. However, it was suggested that adults need a longer duration of patching per day ${ }^{14}$. Longer duration of patching decreases the compliance of patients so this study was conducted to compare the results of visual improvement in young and adults keeping the time of patching constantly in both groups.

In our study, the author's classified eyes into young and adult groups. Only unilateral anisometropic amblyopia was considered so that it is feasible for subjects to follow 4 hourly patching schedules daily. After 12 weeks of occlusion regimen, significant visual improvement was found in both groups and there was no statistically significant difference between the young and adult group regarding improvement.

Recent advances introduced binocular iPad therapy to treat amblyopia ${ }^{15}$. In iPad therapy, red-green anaglyphic glasses are used to see the dichoptic stimulus ${ }^{15}$. PEDIG; a study in which they compare the binocular video games with patching therapy to treat amblyopic eye and study revealed that there was no statistically significant difference in visual improvement between the two groups at 16 weeks ${ }^{16}$. Another similar study was carried out by Manh et al, in older children and it resulted in low visual improvement in the binocular video game group due to poor compliance ${ }^{17}$. It shows that although research is working on a new mode of treatment for amblyopia yet results are comparable to the old method of occlusion therapy. Another study conducted in 2019 showed that combining the passive dichoptic movie viewing with occlusion therapy in adults led to more visual improvement than 
those treated with dichoptic stimulus alone ${ }^{18}$. In addition, the improvement lasted longer and chances of a reversal of amblyopia were very low in patched group ${ }^{18}$.

Amblyopia is believed to be a neurodevelopmental disorder in which there is not only decreased vision but also the binocular visual function is impaired ${ }^{19}$. The image perceived via the amblyopic eye is suppressed by the brain causing monocular blindness. It has been seen that anisometropic amblyopia is more common in older children (3-15 years) $)^{20}$. The increased prevalence of anisometropic amblyopia among this age group makes it necessary to screen the children of this age for uncorrected refractive errors.

There are many ongoing types of research on newer techniques of binocular treatment but is it superior to conventional treatment (occlusion or atropine) is yet to be discovered ${ }^{21}$. A double-blind, randomised, placebo-controlled multicentre trial has been going on in which both older children and adults are being treated with binocular home-based videogames to see improvement in interocular suppression and stereopsis ${ }^{22}$.

Despite significant visual improvement in both groups, there are certain limitations in this study. First of all no increase in patching hours after the initial 6 weeks of occlusion therapy. Secondly, the type of near activities performed by participants during patching hours was different which may influence the result.

Although the purpose of patching therapy is to improve the vision in the lazy eye but as amblyopic patients lack binocular single vision, so recent advances should not only focus on improving the vision but also aim to provide binocular single vision or close to a binocular single vision.

\section{CONCLUSION}

This study demonstrates that patching therapy is advisable to any amblyopic regardless of his/her age. Also after achieving maximum visual improvement, extending occlusion therapy sessions won't lead to further betterment.

\section{Conflict of Interest: None.}

\section{Authors' Contribution}

AA: Data collection and manuscript writing. HM: Final approval and conception. SR: Review of the manuscript. PN: Data collection.

\section{REFERENCES}

1. Braverman RS. Knights templar eye foundation. pediatric ophthalmology education centre., [Internet] Available at https://www.aao. org/disease-review/amblyopia-introduction (Accessed: 29 Oct 2020).
2. Mocanu V, Horhat R. Prevalence and risk factors of amblyopia among refractive errors in an Eastern European population. Med (Kaunas) 2018; 54(1): 6-10.

3. Williams C, Northstone K, Howard M, Harvey I, Harrad RA. Prevalence and risk factors for common vision problems in children: Data from ALSPAC study. Br J Ophthalmol 2008; 92(1): 959-964.

4. Alkhairy S, Siddiqui F, Hasan MU, Prevalence of amblyopia amongst children presenting in a tertiary care centre in Karachi. Pak J Ophthalmol 2016; 32(3): 176-181.

5. Siddiqui AH, Raza SA, Ghazipura A, Hussain MA, Iqbal S. Analysis of association between type of amblyopia and gender at a tertiary care hospital in Karachi. J Pak Med Assoc 2016; 66(5): 545-548.

6. Wright KW. Handbook of pediatric strabismus and amblyopia. New York. Springer 2006, [Internet] Available from: https://www. springer.com/gp/book/9780387279244 (Accessed at: 29 Oct 2020).

7. Angell LK, Robb RM, Berson FG. Visual prognosis in patients with ruptures in Descemet's membrane due to forceps injuries. Arch Ophthalmol 1981; 99(12): 2137-2139.

8. Weakley DR. The association between non strabismic anisometropic, amblyopia, and subnormal binocularity. Ophthalmol 2001; 108(1): 163-171.

9. Agnes MF. New concepts concerning the neural mechanisms of amblyopia and their clinical implications. Can J Ophthalmol 2012; 47(5): 399-409.

10. Park SH. Current management of childhood amblyopia. Korean J Ophthalmol 2019; 33(6): 557-568.

11. Tailor V, Bossi M, Greenwood JA. Childhood amblyopia: current management and new trends. Br Med Bull 2016; 119(1): 75-86.

12. Informed Health. Cologne, Germany: Institute for Quality and Efficiency in Health Care (IQWiG); 2006. Lazy eye (amblyopia) in children: What are the treatment options for lazy eye (amblyopia)? [Updated 2020 Jun 4], [Internet] Available from: https://www. ncbi.nlm.nih.gov/books/NBK279463/ (Accessed at: 29 Oct 2020).

13. Gopal SK, Kelkar J, Kelkar A, Pandit A. Simplified updates on the pathophysiology and recent developments in the treatment of amblyopia: A review. Nat Inst Ophthalmol 2019; 67(9): 1392-1399.

14. Wallace DK, Lazar EL, Crouch ER. Time course and predictors of amblyopia improvement with 2 hours of daily patching. J Am Med Assoc Ophthalmol 2015; 133(1): 606-609.

15. Kraus CL, Culican SM. New advances in amblyopia therapy I: binocular therapies and pharmacologic augmentation. Br J Ophthalmol 2018; 102(1): 1492-1496.

16. Holmes JM, Manh VM. Effect of a binocular ipad game vs part-time patching in children aged 5-12 years with amblyopia: a randomized clinical trial. J Am Med Assoc Ophthalmol 2016; 134(2): 1391-400.

17. Manh VM, Holmes JM, Lazar EL. Pediatric eye disease investigator group. a randomized trial of a binocular ipad game versus part-time patching in children aged 13 to 16 years with amblyopia. Am J Ophthalmol 2018; 186(1): 104-115.

18. Sauvan L, Stolowy N, Denis D, Matonti F, Chavane F, Robert F, et al. Contribution of short-time occlusion of the amblyopic eye to a passive dichoptic video treatment for amblyopia beyond the critical period. Hindawi 2019; rticle ID 6208414, [Internet] Available at https://doi.org/10.1155/2019/6208414

19. Wallace DK, Repka MX, Lee KA, Morse CL. Amblyopia preferred practice pattern®. Ophthalmol 2018; 125(1): 105-142.

20. Al-Haddad C, Ismail K, Jurdi KW, Keaik M. Clinical profile and treatment outcomes of amblyopia across age groups. Middle East Afr J Ophthalmol 2019; 26(2): 71-76.

21. Marianne EF, Anita J. Simmers. It's too late'. Is it really? Considerations for amblyopia treatment in older children. Ther Adv Ophthalmol 2019; 11(1): 2515841419857379.

22. Guo CX, Babu RJ, Black JM. Binocular treatment of amblyopia using videogames (BRAVO): study protocol for a randomised controlled trial BMC. Trials 2016; 17(1): 504-513. 